This is a post-peer-review, pre-copyedit version of a Book Chapter published in the book.

Thinking University: A Philosophical Examination of Thought and Higher Education

The final authenticated version is available online at: 


\section{A Complexity Thinking Take on Thinking in the University}

David Beckett \& Paul Hager

\section{Introduction}

Universities are explicitly sites of thinking: they present myriad ways to think - and to provoke thinking. Heidegger, in his famous work 'What is Called Thinking?' (1954) marks out the relational quality of thinking, thus: 'thinking is thinking when it answers to what is most thought-provoking' (p28); and 'we learn to think by giving our mind to what there is to think about' (p4). Both 'answering' and 'giving' are examples of thinking relationally, that is, by doing it under provocation - it is in the doing of thinking that our learning emerges. In this chapter, we develop the significance of this 'learning thinking by doing thinking' to which Heidegger draws attention, and we do so by setting out a contemporary account of complexity. First, we provide a theorisation of complexity, which comes across from the natural sciences to the social sciences, though in a somewhat different form. Secondly, we put this theorisation to work, in raising some challenges and opportunities for re-thinking thinking for universities, by tackling some of the big issues facing learning in universities. These include excessive individualism, narrow cognitivism and an emaciated notion of learners' agency, all of which under-acknowledge the formative power of groups, especially for shaping subsequent professional practice broadly conceived. We close with some practical implications for universities' core work of this complexity thinking 'take' on thinking.

\section{Why complexity thinking has come to the fore}

Complexity thinking begins with the observation that humans inhabit a world that is infinitely complex. As Richardson and Cilliers (2001) note, complexity is ubiquitous. Humans employ complexity reduction in order to cope with this overwhelming complexity of the world. We make sense of it by focusing on some features and ignoring others. Much complexity reduction is done for us thanks to biological evolution. Humans are equipped with complexity-reducing sensory structures. Nevertheless, as this chapter will argue, particularly 
in the domain of the social, humans also have significant freedom to choose the degree of reduction that will be serve their given purposes.

Since complexity has all along been a feature of our world, one might well ask why it is only comparatively recently that it has begun to receive serious attention. Morin (2007) credits the advent of the second law of thermodynamics and concepts such as disorder and chaos with science's increasing acceptance of complexity. As the concept of complexity gradually proved its value to the natural sciences and mathematics, it became influential in the fields of philosophy and the social sciences. The term 'complexity' has also come to be understood somewhat differently between disciplines, and even within the same discipline (Byrne and Callaghan, 2014). Thus, there has been growing debate about the essential features of complexity, with distinctions emerging between different kinds of complexity.

This diversity of theories lies behind our preference (following Richardson and Cilliers 2001) for the term 'complexity thinking' rather than 'complexity theory', complexity thinking being a useful tool for reflection about our ontologically complex world and our interactions with it.

\section{An overview of complexity thinking}

Firstly, complexity is a property of systems. Very familiar are simple systems. Their states can be specified readily and their operations can be described in linear terms using Newton's Laws. Though simple systems can be intricate, their states and operations still can be specified and accurately described. Such simple systems are better described as complicated, rather than as complex. A state of the art submarine or a Boeing 747 are examples of complicated yet simple systems. Genuinely complex systems are something very different. They elude understanding and description via linear mathematics and Newton's Laws. In a complex system, "the causal categories become intertwined in such a way that no dualistic language of state plus dynamic laws can completely describe it." (Rosen 1987: 324). Put more simply, a complex system is "a set of inter-related elements ....in which ...the whole is greater than the sum of its parts." (Byrne and Callaghan 2014: 4) (Although, as will become clear, this formulation needs careful interpretation.).

Secondly, complexity arises from the relations between entities, rather than from the entities themselves. Extending the first point, complex systems are characterised by multiple non- 
linear relations between the entities within the system. It is the interaction of these non-linear relations that can give rise to new structures or qualities which, though constrained by the original relations of the system, are not wholly predictable from them, nor reducible to them. This phenomenon, known as emergence, is a characteristic feature of complex systems. Any understanding of complexity must include a careful investigation of the relations (interrelationships) between entities, rather than the traditional focus on the entities themselves, i.e. on the relata.

The focus on relations challenges more familiar modes of thinking. Some philosophical views seek to subsume relations into the particulars (relata) between which the relations hold. This approach, which effectively reduces relations to properties of their relata, might be called the 'Lego view' of relations - mere collections of suitably shaped particulars. Scepticism about the ontological reality of relations has been fuelled further by the apparent reification of relations by some relational realists, that is, in making reference to relations, they seemingly treat them as things (particulars, substances) on a par with non-relational things or entities. This practice is mistaken.We are also sceptical of representational assumptions: where what there is is already 'out there', pictured for us in language, or perception as a 'given'. For us, by contrast, the activities of life shape experiences, including experiences of relatedness, as well as of the complexity of the relational reality within which relata and their relations persist.

In order to illustrate the dominance within Western thought of a substantialist perspective, Emirbayer (1997) points to the statement that 'the wind is blowing'. Here the implication is that a discrete particular, the wind, is engaging in the activity of blowing. In truth a more accurate description of the wind blowing would consider relational differences across various parts of the earth's atmosphere.

Similarly, the Western world is shaped by natural languages where nouns-and-verbs represent experience atomistically: we 'see' these first when we describe the world. By contrast, for those from some indigenous experiences, what is 'seen', for example, is not a 'canoe-on-abeach' (that is, atomistically, a canoe and a beach in a relationship), but 'canoe-on-ness' (a relationship, within which relata make sense) (Watson-Verran 1989 p14). In subsequent work on indigenous relationality, Watson-Verran draws on the later Wittgenstein to claim that how we act in the world is bound up with how we see and communicate: '...particular 
predicating-designating... originates in language-users' embodied certainty of relationality in acts' (Verran, 2001, p224).

Overall, and for various reasons, relations have been viewed widely as being ontologically suspect and theoretically superfluous. It is clear then that a complexity perspective, insisting that complex systems are constituted by the relations between entities, rather by the entities alone, poses a direct challenge to much established thought, and to traditional 'thinking'.

Thirdly, the term 'reduction' has occurred severally in this chapter. Reduction of complexity - some of it biologically programmed, some consciously chosen - has been proposed as a major mechanism for human coping with a complex world. Reduction has also been presented as one of the fundamental explanatory principles of science. There it can be a knowledge claim: an understanding of the basic constitutive elements of a composite is sufficient for knowledge of the composite. Or it can be an ontological principle: composites are nothing more than the sum of their basic constitutive elements.

What is common to each of these citings of reduction is that either the relations within the whole (or composite) are ignored or a minimalist understanding of the relations is adopted. Such reductions are undertaken for a variety of purposes. For example, musical works written for large scale forces, such as singers and orchestra, are reduced to a piano version to facilitate the early stages of rehearsals when the orchestra is not yet available. Likewise, simplified arrangements of famous, yet advanced, piano pieces are developed to enable beginning pianists to have some experience of this music. In such instances, the purpose is often a pragmatic reduction to make the best of particular circumstances. In addition, these examples suggest that reduction is commonly a matter of degree. For instance, arranging a symphony for solo piano would be more reductive than an arrangement for a chamber orchestra.

In the sciences, somewhat different purposes of reduction become evident. In some cases, there is acceptance that the complexity of the world cannot be taken into account all at once. The mathematics would be far too complicated for an initial 'all or nothing' approach. Thus, theories and models are constructed that deliberately simplify. These are then tested, refined and developed further till their predictive power approximates reality. Models are reductive conceptual tools that are refined empirically to take account of limited, but key, aspects of 
natural or controlled systems. As such, they ignore the roles of certain relations and interactions, for example, 'ideal' gases are assumed to have negligible interactions between the gas molecules. Statistical modelling is a related reductive strategy that provides quantitative data on many phenomena. In the modern era, statistical tools such as surveys, budgets, maps, and accounts, have become essential underpinnings of bureaucratic administration within nation states. Social life in general is an instance of complexity reduction. Social norms that shape human interaction and communication bring order and even routine to situations that otherwise would be complex in the extreme. Similar considerations apply to human behaviour within particular organisations, institutions, and communities. Each has evolved its own distinctive form of complexity reduction, its ethos, identity, and particular ways of doing things ('organisational culture' is often defined as 'how we do things around here').

There are, therefore, many reasons for complexity reduction, and multiple ways of doing so. They are often unnoticed and unacknowledged. Common to all is the downplaying or ignoring of specific relations. Thus, complexity reduction strategies offer tacit support to scepticism about relations in the overall furniture of the world. Another drawback is that by treating relations reductively while focusing on particulars, it leaves our dominant conceptual frameworks less open to the more process-oriented, generative aspects of human functioning, aspects characterised by their relationality.

Take the theorisation of meaning. The dominant focus on particulars has seen many attempts to understand meaning as fixed or precise, though none has gained lasting acceptance. We endorse Malpas (2002), who has argued that meaning is inescapably relational, being always context dependent. On this view, meaning can never be fully determinate since it is always 'in the making'. Thus, complexity thinking strongly suggests that the presuppositions that structure our conceptual frameworks themselves need to be the subject of searching inquiry. In addition, as Cilliers $(2001,2013)$ stresses, complexity thinking points to the necessary incompleteness of all theorising. It follows that complexity thinking is necessarily incomplete, and so it is not so much a replacement for other theories as a useful adjunct.

Crucially, for complexity thinking, the relations between entities have ontological salience. But this should not be understood as implying that entities (or particulars) are irrelevant. According to complexity thinking it is the processes of the relations between entities that are 
central. From a complexity perspective, structure is not a mere assemblage of entities but is emergent from these processes of the relations.

The next section of this chapter centres on how certain types of group processes favour emergent thinking within universities. For emergence to occur, we need groups that are complex systems, not just simple, or even complicated, systems. The difference is that for complex systems, which are, of course, nonlinear, changes can be "disproportionate to the changes in the causal element(s)" (Byrne and Callaghan 2014: 18). As Nicolis puts it:

In a linear system the ultimate affect of the combined action of two different causes is merely the superposition of the effects of each cause taken individually. But in a nonlinear system adding two elementary actions to one another can induce dramatic new effects reflecting the onset of cooperativity between the constituent elements. This can give rise to unexpected structures and events whose properties can be quite different from those of underlying elementary laws.... Nonlinear science is, therefore, the science of evolution and complexity. (1995: 1-2)

Thus the strong connection between the nonlinearity of complex systems and the phenomenon of emergence is crucial. This has both ontological and epistemological implications. The ontological point is that our account of 'what there is' needs to include the emergent properties that characterise complex systems. Emergent properties are irreducible to the properties of the individual components of the complex system. The epistemological point is that, without an account of these emergent properties, any understanding of reality will be defective.

Complex systems are also open systems, in that they can exchange material and/or information with their environment. They feature internally generated processes, i.e. selforganization. However, and importantly, there are also different types of complex systems, as marked by Morin's (2007) influential distinction, between "restricted complexity" and “general complexity" (see also Byrne 2005, Lancaster 2012).

\section{Restricted complexity}

Restricted complexity is "the emergent product of interaction amongst simple agents", i.e. the complexity that "emerges from rule-based interactions among simple elements" (Byrne and 
Callaghan 2014: 5). As Morin points out, though it has led to "important advances in formalization, in the possibilities of modelling", it is "firmly anchored in the epistemology of classical science" (Morin 2007: 10). That is, it adheres to explanatory principles of classical science, principles that Morin argues have served to mask the significance of complexity. Specifically, as its focus on rule-based interactions among simple elements suggests, restricted complexity adheres to the principle of reduction. It is characteristic of restricted complexity that the micro-level of the system is at the physical level, thereby preserving key features of the Newtonian science framework. At the same time, it is accepted that restricted complexity arises from non-linear relational interactions. However, the emergents from the processes of these non-linear relational interactions are patterns or networks, which can be subject to algorithmic formulation and computation. The general idea is that for restricted complexity, if only we have sufficient information we can, in principle, 'explain' any emergent:

An oft-quoted instance of 'simple components interacting simply' is the formation of sand dunes. Simple relations between multiple grains of sand, powered by various environmental forces over time, produce a sand dune. Further applications of restricted complexity to understand complex phenomena include bird flocking, traffic flows, voting behaviour, and patterns of disease. It is notable that in each of these instances the individual birds or humans are treated reductively as statistical variables, similar to grains of sand. These successful uses of restricted complexity represent its extension from mathematics and the natural sciences, into the social and human sciences. However, it soon became apparent that this reductive form of complexity has limited applicability in the social and human sciences. It breaks down where humans need to be treated as distinct individuals and the specific interpersonal relations between individuals are relevant to the particular focus of the inquiry. In such cases, it is uninformative to view individual persons reductively as statistical variables. At best, restricted complexity provides broad-brush understandings of organisational, institutional or population-based aspects of social functioning. To appreciate the wider possibilities for applying complexity thinking to the social and human sciences we need to consider another kind of complexity - general complexity.

\section{General complexity}

Morin introduces general complexity by contrasting the respective "paradigms" of classical science and of complexity thinking. He views the knowledge paradigm of classical science as 
one of simplification regulated by "a principle of reduction and a principle of disjunction". In contrast, the knowledge paradigm of general complexity features "a principle of distinction and a principle of conjunction" (2007: 10). Morin characterizes general complexity as follows:

In opposition to reduction, [generalized] complexity requires that one tries to comprehend the relations between the whole and the parts. The knowledge of the parts is not enough, the knowledge of the whole as a whole is not enough, if one ignores its parts; one is thus brought to make a come and go in a loop to gather the knowledge of the whole and its parts. Thus, the principle of reduction is substituted by a principle that conceives the relation of whole-part mutual implication. (10)

Whereas restricted complexity remains as faithful as possible to three fundamental explanatory principles of classical science, Morin characterises general complexity as substituting three contrasting principles. As the above quotation suggests, the principle of reduction is replaced by a principle of whole-part mutual implication. Likewise the principle of disjunction is replaced by a principle of conjunction. That is, while recognising the distinctions between things, we also need to take proper account of the relations between them (Morin 2007: 11). Finally, for the principle of determinism, Morin (2007: 11) substitutes a "principle that conceives a relation between order, disorder and organization". Morin's elaboration of this principle centres on the key terms - system, emergence and organization - and the relationships between them. Byrne and Callaghan (2014) strongly support the importance of Morin's general complexity for the social and human sciences:

....any general complexity social science has to get beyond micro-determined emergence. It has to allow for structures with causal powers and it has to address human agency as capable of transcending narrow rules for behavior. (2014: 56)

Vital to general complexity is that individual humans are themselves complex systems (Byrne and Callaghan (2014: 41). This makes them more complex in many ways than the rulefollowing agents in the agent-based simulations that exemplify restricted complexity. In general complexity, humans have the power of agency both individually and collectively. In positing collective agency, Byrne and Callaghan maintain that "collectivities have a reality beyond the individuals who constitute them" (2014: 41). This idea opens up the important 
concept of

....the ontological reality of nested and interpenetrating complex social systems beyond individuals, although of course with individuals as elements in those systems... (2014: 41)

Byrne and Callaghan view social systems and entities as both nested and interpenetrating with causal powers running in all directions (2014: 45). They summarise this idea as follows:

.....there is a 'social' at whatever level from the smallest collective assemblage of human beings to the level of the world system as a whole. The social we see as emergent but not simply as emergent from individual interactions. There is a reality within which all the entities operate, interpenetrate, and mutually and reflexively express causal powers. (2014: 45)

\section{Putting Complexity Thinking to Work in Universities}

Universities are sites of human thinking, where provocations are, as it were, built in to the mission. Emergence of knowledge, filtered through rigorous critical scrutiny, is at the heart of scholastic and of research activities. Learning-to-learn involves coming to understand oneself as part of communities and cultures which already relate to the wider world as well as to various parts of the university, such as through (traditionally) disciplines, or (currently) 'wicked problems'. Evidence of achievements in scholarship and research, and therefore in teaching, is typically taken to signify 'truth': all these arise from powerful thinking which is relational and organic - always on the move and yet embedded in traditions of thinking which construct identities. As Heidegger (1954) asks, 'what is it that calls on us to think?', and, 'by thinking, be who we are?' (p121). He asks, what is our food for thought? In universities, we become thinkers (that is, assume the identity of a thinker) because we are appropriated, that is, joined, to thought.

Traditionally, and by contrast to the Heideggerian view, universities have engaged our thinking by joining us to thoughts - in the sense of accessing items, or imbibing atoms of 'food', to think about (also known as propositional knowledge). This has traditionally occurred through three assumptions about, or 'appropriations' of, experience: 
- Universities readily atomize human performance into component parts. Traditionally, lectures give theories, and the tutorials or laboratories give applications of these. The sum of these experiences is then assumed to be equivalent to the original whole. Complexity thinking suggests this is unhelpfully reductive of human experience.

- Universities focus on the more overtly cognitive aspects of human performances. Traditionally, the learning that is privileged is the ordering (in a lecture and a library) and re-ordering (in a tutorial or examination paper) of propositions (or 'knowing that $\mathrm{x}$ '). This generates 'thin' understandings that overlook other crucial aspects of experiences, such as affect, know how, judgement, and the various influences of context.

- Universities traditionally assume that the individual agent is the appropriate unit of analysis for understanding human performances. If 'I' get it right, I will do well. Yet the atomised 'me' typically has a thoroughly social campus experience, in groups most of the time, at least formally. This assumption fails to acknowledge the sociality of university learning.

Complexity-inspired understanding of what a university is, or (in Heideggerian terms), how such an understanding 'calls forth' or provokes thinking, challenges these three traditional appropriations of experience, in particular by:

- Insisting upon holistically relational understandings of the interactions within human performances.

- Recognising the roles of the affect and other non-cognitive attributes in the judgments involved in human performances.

- Taking groups as the focus of analyses, within which the roles of the group can be synthesised in judgments.

Why this emphasis on groups? Small groups of people (say, between two and a dozen) working cooperatively to achieve common goals are major ubiquitous features of the human world, and are very prominent though under-recognised, in the ways universities are structured and function. Complexity thinking brings these features to prominence, and indeed advocates small groups as a logical extension of this prominence, in the particular 
case of universities as sites of thinking.

Universities require myriads of small groups to function under a wide variety of names according to particular circumstances: executives and committees, research centres and hubs, teaching teams and programs, departments and offices and so on. Even when research papers require hundreds of co-authors' names, this frequently reflects a federation of smaller groups working in labs in various locations, all contributing to the final effort. At the other extreme, a single-authored humanities book will often be underpinned by a team of research assistants. Overall we can see that university research infrastructures, and their purpose and functions, are well-explained by complexity thinking.

The provocation of thinking, which is the mission of a university, to which all these structural small groups are intended to contribute, also requires small pedagogical groups: tutorials, laboratories, study and writing groups, workshops, seminars and excursions, and work-integrated learning (which implants learners away from the university into other organisations' small groups). Similarly, these sites of 'thinking-provocation' mirror the wider world, such as family life, book clubs, community choirs, surgical teams, legal teams, swimming squads, and so on. All these provoke thinking, but for universities, it is their main pedagogical mission to do so, not as a consequence of other activities.

Small groups have a shared purpose and a shared commitment to achieving that purpose, albeit for the good of the individuals within the groups, as well as for the groups. That is why complexity thinking as we set it out here is less reductive, not non-reductive. There is a legitimate expectation shared by members of a small group, namely, that each individual will benefit from her or his membership of it (cf. Simpson \& Beckett 2014). So our account of complexity is 'general' in the sense that it minimises reduction to the atomistic, whilst acknowledging the legitimacy of particular expectations held by individuals. But our ontological priority is general relationality: how groups as sites of practice (and therefore of identity) generate, through their relationships, these practices and identities. Within this ontology, the particular relations of individuals to each other and to the group (which altogether give the group's activities its purposes - its telos), are what give the group an identity as a group.

Our emphasis on complexity theory, defined earlier as the general or over-arching relations of 
the parts (the individuals and their relations) to the whole (the group), flows logically through to our claim that universities are sites of complexity thinking. Small groups are ubiquitous in universities, as we showed earlier. Now we refine the notion of small groups.

What do university-based instances of small groups at work have in common? Most obviously, and most generally, these groups focus on a shared process towards a shared goal. In replacing the lone university student as the archetypical 'thinker', we propose the notion of the 'co-present group', a type of complex system defined by and constituted in:

- an ontological prioritisation to the relationships of the group - which contain 'thought-ful' experiences amongst the individuals who are members of it, both to each other, but also to the group as a whole;

- a holistic appreciation of affective group experience, not merely of the cognitive (traditional thinking or ratiocination); and, arising from those two characteristics, this leads to:

- an assumption that these relationships and experiences are constitutively social - that is, they give the group its identity as a group, as knowledge emerges from shared understandings (note that these understanding do not assume 'agreement': it is common to agree to differ).

'Co-present groups' (Lancaster 2012, 2013) are ways of addressing shared purposes; these particularities consist in acknowledging the 'provocative' potential of the relational processes of such groups. Complexity thinking thus directs attention to the generative significance of 'thought-ful' experiences within groups - including cognitive, affective and social phenomena. These experiences are inevitably (since they arise amongst humans) messy! Recall that our account of general complexity in the previous section drew attention to the significance of emergence, where what emerged was unpredictable and not reducible to the relations from which it arose. For a much fuller discussion of general complexity, emergence and their exemplification in co-present groups, see Hager and Beckett (forthcoming). 
University tutorials and laboratories, as examples of working in co-present groups, are generative of thinking, but cannot predict, nor can they retrospectively explain, their outcomes. Complexity thinking, as manifest in co-present groups in universities, provokes the emergence of better thinking, but does not go the next step: setting up the 'best' outcome.

We now take this a little further.

The 'co-presentness' of a group is constituted by the willingness of the members to own its relational, holistic and social significance. A co-present group is engaged in a shared endeavour: the makings of meanings (that is, sense-making) of some aspects of the world in which the group operates. This is fundamental to the mission of a university, but a copresent endeavour does not insist on shared agreement as an outcome of the group's functions. A co-present group, such as a tutorial, workshop or laboratory, therefore has an onto-epistemological significance: it exists to seek understandings of, and to progress, some significant experiences towards these becoming knowledge in and of the world. Thinking is 'called forth', or generated, by the co-present group. Diverse makings of meanings are expected to emerge from the complexity thinking inherent in such groups.

But how can this occur? Not surprisingly, affective relations between co-group members are vital to seeking and progressing these significant experiences. Similarly vital are tacit (inarticulable, and typically embodied) experiences. 'We know more than we can tell', famously stated Polanyi (1966; p4).

Because we are defining the co-present group as constituted by its relationality, its holism and its sociality, we believe the ideal size of such groups is between two and about twelve members, and they do not have to be physically present. A virtual or semi-virtual co-present group may exist across the globe, and may include some members in the same room at the same time. Moving further into double figures increases the relationships exponentially and unrealistically complicates expectations of shared experiences from which shared understandings and new knowledge can readily emerge. The affective and the tacit would be two early casualties of a larger group trying to act 'co-presently'.

Instead of formal management, we believe co-present groups are structured through 
sensitivities to the performative nature of their relations. Hence the inherent messiness of copresent groups, as we noted earlier. Performances can range from the tightly scripted to the completely improvised. Members of groups are changed by their own, and others', diversely performative participation in them. This is 'transactional' activity (cf. Dewey \& Bentley 1949), because both relations and the entities (relata) related by them, are altered by participation in them. In the tutorial or workshop, participation changes relationships and those who are in the room.

So, for us, co-present groups are constituted in transactionally-relational activities. In particular, the onto-epistemological significance of a co-present group is apparent in how it makes experiences meaningful: this is found through undergoing performative activities where affective relations, and the tacit, are shared. In universities (both in their research and also in their pedagogical functions), learning, and thinking, emerge by doing these activities. 'Sharing' and 'undergoing' are relations. This is the heart of a retrieval of a thinking university, but one that is informed by complexity thinking.

Heidegger (1954) reminds us of our legacy: '[O]ur own manner of thinking still feeds on the traditional nature of thinking, the forming of representational ideas' ( $\mathrm{p} 45)$, shaped, in the West, by logos (p163). Under complexity-informed thinking, we move beyond the traditional 'representational' account of thinking and the cognitivism that it assumes - where ideas are transmitted as propositions from libraries, their books, and from the memories of academics, into the heads of learners. Instead, following this insight, we propose co-present groups as sites of provocations (or 'callings forth') to thinking, where provocations are a form of doing ideas, not of transmitting ideas. In universities, co-present groups 'share', and learners 'undergo', what is generative - namely, thinking, out aloud (that is, with each other).

Of course, in these 'doings' (both the sharing and the undergoing), propositional knowledge is essential, and the significance of teaching from 'representational ideas' is profound. Thinking aloud (in language) would be Babel without direction and leadership in what to think about - provocations as mere provocations can be mindless and trivial. Heidegger notes that: 'We are capable of thinking only insofar as we are endowed with what is most thought-provoking' (p126). We are called, through the shared experience of conversations, that is, in language, into acts of more-or-less 'sense-giving' (p129). Sense-making, or 
meaning-making, is the pedagogical challenge, no less so under complexity thinking. Sound university teaching directs learners to start with what we know or make sense of (commonly), and work out the 'well-springs' (that which is the most generative) which are 'dug up in the telling' (p130). And for us, co-present groups require leadership, in the direction of 'what there is to-be-thought', where the food, or well-springs, are most likely to nourish thought. Co-present groups need leadership - there needs to be a director of the research, and a lecturer/tutor of the class. This is fundamental to co-present groups in a university. Knowledge which emerges from co-present groups needs to be shared authoritatively - by which we mean underpinned by norms of rigor, which experts have as part of their expertise in the field of research or pedagogy. Astronomy cannot be allowed to drift into astrology!

The other significant relation in 'doing' thinking is 'undergoing'. A co-present group has an immediacy born of the generative activities which are shared. The group has to stay with the telos, with what is the focus: 'Present and presence means what is with us. And that means: to endure in the encounter', states Heidegger (p234). Staying with the activities, and knowing that is important, brings with it sustained exposure to thinking. Thinking in learning situations through co-present groups (in contrast to the traditional atomistic and cognitivist account) exposes individuals to learning about each other and about themselves, through what is relationally undergone.

On the way through to an outcome (whether agreed or not) - say, a judgement that this is indeed valuable learning, or new knowledge, or worth thinking about - the group's affective and social functioning intertwine over time. Time and being are thus co-implicated in the existence of the co-present group. Following Heidegger (1954 Lecture $X$ passim), time is both always experientially present, and also is always 'the present', even when the past and the future are engaged in teaching, in propositions, through memories of earlier research, or in plans for proposed future work. So, co-present groups in universities are marked by persistence over time, and are 'in' time, where the time is the present, as a feature of their 'doing thinking'.

We want to take this retrieval of thinking into the equally-significant vocational mission of a university. Co-present groups in universities are heavily involved in the educational formation of future workers in the wider world, mainly, professionals. And in, and for, this 
wider world, vocational success is frequently attributed to teams, projects and interdisciplinary practices all of which instantiate our three complexity-driven features: holistic relationality, affective functioning and the sociality of the workplace. Co-present groups can also exhibit agency (cf List and Pettit 2011). Such a group can in itself (without reduction to the actions of individuals in it) make a difference in the world and be accountable for it. The power of 'thinking' in and beyond university experiences via co-present groups is profound, as Carol Rovane explains, in entering the debate over groups and agency:

When philosophers are open-minded about the possibility of group agency, they accept...that a group of human beings can realise, or at least approximate, at the level of the whole group the same kind of rationality that is characteristically realised by normal adult human beings (Rovane, 2014, p1663).

Since 'co-present groups' are co-constitutive of thinking and doing, it comes as no surprise to read that expertise (and skills, and competence) emerge from relations, where affective functioning and the sociality of work are paramount. In setting out an account of such vocational formation, Anne Edwards (2010) draws attention to:

...the relational turn in expertise as professionals work in and between work settings and interact with other practitioners and clients to negotiate interpretations of tasks and ways of accomplishing them. The central argument is that the resources that others bring to problems can enhance understandings and can enrich responses. However, working in this way makes demands on practitioners. At the very least, it calls ... the capacity to recognise and respond to what others might offer. (p13 emphasis added)

We think better amongst others! Confident engagement and a capacity to recognise and respond to what others might offer are features of working together in a team environment on a project, such as a surgical operation (e.g. Bleakley 2006), a lawsuit, an art exhibition or performance, the construction of a building and so on - through the many associated generic capacities such as: communicability, problem-solving, conflict resolution, literacy, numeracy and so on.

These 'thinkings-and-doings' should be explicitly apparent in most learning activities, such as simulations, role plays, skills training, job rotations, formal studies and so on (Beckett, 
2012a, 2012b). Outside universities, an entire vocational education and training sector exists, from which much can be learned about the power of co-present groups in professional and other labour-market configurations (such as trades, casual work, franchise operations).

What is required is an account of the agency of the co-present group in generating the emergence of expertise of the kind Edwards calls for, that is, which is relational. By this, she means that, in the workplace, responses and solutions to particular situations that arise there emerge from the relational processes - the myriad, messy but purposeful decisionality that a group generates as it grapples with routine, non-routine and sheer unintended circumstances: the happenstance of life at work. Informal learning frequently and powerfully arises from this messiness, (Hager and Halliday 2006, pp235-238).

So, our co-present groups possess an agentive capacity, and their expertise is found in their affective functioning, as much as in their social characteristics. The co-present group's decisionality emerges from its socio-affective activity. Its outcomes are the group's outcomes; its processes are equally integral to the group.

A co-present group has agency constituted in human experiences that are holistic, and are significantly affective: we want and desire various 'goods'. Life is normative, and the particularity of this - locations of practice - no less so. The ethos of nursing, for example shapes the practical judgements and decisions of nurses: what counts as an improvement in wellness for the patient in Bed Three is driven as much by normativity as reasoning: both are involved in a clinical judgement made by nurses in the Post-Operative Ward. Indeed these are intertwined. What counts (to peers) as a 'good' reason is, by definition, normative. Its 'goodness' is found in its normative fitness, according to the ethos of the practice.

So our co-present groups - both in universities and beyond them in the vocational world that normally follows - advance practical purposes and are thus constituted in the quest to achieve them, through the decisions (or judgements) made by the group. Aristotle argues that judgements that are practically wise are about ' ... what is to be done. For the originating causes of the things that are done consist in the end at which they are aimed' (Nichomachean Ethics, Bk 4, Ch5). So, we see how, in co-present groups, normativity constitutes practical judgements: the reasoning and the justifications for actions which peers and individuals have and can give one another are enfolded within what it is to be, not just a human-with-agency, but more particularly a group of (nascent) practitioners-within-a-practice. This embedded, constitutive agentive capacity is part of who we are, at and through our work. It gets us 
moving. Moreover, there is a larger claim. Our group-based agency helps to make us ontologically distinctive - how (and how well), and with whom, we do our work, makes us who we are, and so identity is an emergent property, spinning off from deep within our evolving purposes - what Aristotle calls 'good actions'. As Edwards (2010) sets out:

...identity is not a stable characteristic, but is dialogical, negotiated and accomplished within activities...which are in turn located in practices. ... One's identity is also an organising principle for action: we approach and tackle what we think we are able to change and make changes in line with what matters to us: our interests. These interests are culturally mediated, but nonetheless experienced personally in terms of our commitments, standpoints and the resources available to us. (p10)

In a world increasingly sensitive to the 'relational turn', our agency is itself in the relational mix. Practitioners, including researchers and pedagogues in universities, act amongst the fluidity of daily work, so our experience of our agentive selves is itself a component in the construction of our identity. 'Academic freedom' is an aspect of the identity of the university practitioner, prized and defended at least in the West, and it has emerged from the ideal of the autonomous pursuit of truth. This normativity assumes agency. In universities, we typically 'see' ourselves as more or less agentive, depending on the practical exercise of that 'relational agency'. To re-iterate, most of our daily university work revolves around and amongst small groups and the thinking which they generate. But can our very sense of agency emerge from complexity thinking in co-present groups, as such?

Deborah Perron Tollefsen (2015) has recently set out an account of joint intentionality and collective responsibility. She argues that this depends on making sense of others, by attributing to others 'a unified perspective - a rational point of view - and that [the group] shares our norms of rationality... [thus] we attribute beliefs, intentions and desires [to groups] in the same way we do to individuals' (p104). Tollefsen claims our practice of interpreting the actions of groups is 'just an extension of our practice of making sense of individuals' (ibid.). Thus her claim fits with the model of complexity theory we have developed in this chapter, namely, as we stated earlier, to give onto-epistemological prominence to the 'general or overarching relations of the parts (the individuals and their relations) to the whole (the group)'. We claim that thinking is a prominent manifestation of this 'group agency', particularly through the myriad co-present groups experienced in universities. 
Co-present groups in and beyond universities, therefore, are central to the formation of vocational identities (including the identities of academics), and, indeed to the formation of adults-as-citizens who are confident participants in society. This latter outcome is the traditional virtue of a university experience, now, re-vitalised through complexity thinking, especially through the notion of co-present groups wherein agency is embedded.

\section{Conclusion - Thinking Relationally}

Universities are sites of human intellectual endeavour where all learners expect to be changed for the better, and, within this, some major institutional and national structures and systems are dedicated to professionals' formation and development. Both traditional and current frameworks of the 'vocational' are simultaneously apparent in how universities are structured and operate - stridently 'vocal', as institutional identities compete across the globe. Thinking is called for, and claimed, everywhere.

Our 'take' on thinking started with Heidegger's 'calling forth' of thinking by which he meant the vocalisation of thinking as a manifestation of our very being. Discourses, conversations and the doing of learning are symbiotically related as the very stuff of a university. We have set out how complexity thinking challenges traditional onto-epistemological assumptions about the learner ('student'), her state of knowledge, her capacity to change, her teacher ('lecturer') and her capacity to transmit knowledge - and all the relations implicit herein. We have called here for a reversal of the implicit assumption that relations are residual phenomena of university experience.

By contrast, general complexity thinking requires persistence with university structures and practices which start with relationality: how relations stand up to, shape and encompass entities such as learners, teachers, knowledge and professional formation. Expertise, and skilled performances, in all these respects, are better regarded as emergent phenomena where co-present groups are fundamental in university life. We advocate what we call 'thinking relationally', as the constitutive characteristic of the Thinking University, and we see this as a provocation in the Heideggerian sense - it is 'food for thought', which should be a gastronomic metaphor informing every faculty, department, research centre, chat-room and quadrangle as pedagogies, assessments, qualifications, and registrations, and, yes, even as alumni events are re-shaped. Thinking relationally is mission-critical for a university worthy of the name. 


\section{References:}

Aristotle (R McKeon Ed.) (1941). Basic works (New York: Random House)

Beckett, D. (2012a). Ontological distinctiveness and the emergence of purposes. (In P. Gibbs (Ed.), Learning, work and practice: New understandings. (pp. 69-84) Dordrecht: Springer).

Beckett, D. (2012b). Of maestros and muscles: Expertise and practices at work. (In D. Aspin and J. Chapman (Eds.), Second international handbook of lifelong learning. (Part One, pp. 123-127) Dordrecht: Springer).

Bleakley, A. (2006). A common body of care: The ethics and politics of teamwork in the operating theater are inseparable. Journal of Medicine and Philosophy, 31, 305-322.

Byrne, D. \& Callaghan G. (2014). Complexity theory and the social sciences: The state of the art. (London \& New York: Routledge)

Cilliers, P. (2001), Boundaries, hierarchies and networks in complex systems. International Journal of Innovation Management, 5 (2), 135-147.

Cilliers, P. (2013). A crisis of knowledge: Complexity, understanding and the problem of responsible action. (In P. Derkx \& H. Kunneman (Eds.) Genomics and democracy: towards a 'lingua democratica' for the public debate on genomics. (pp. 37-59) New York: Rodopi.)

Byrne, D. (2005). Complexity, configuration and cases. Theory, Culture and Society, 22 (5), 95-111.

Dewey, J. \& Bentley, A. (orig 1949; 1989) Knowing and the Known. (In J.A. Boydston (Ed.) John Dewey: The later works 1949-1952, (Vol 16, Ch 4, pp. 2-294) Carbondale: Southern Illinois Press.)

Edwards, A. (2010). Being an expert professional practitioner: The relational turn in expertise. (Dordrecht: Springer)

Emirbayer, M. (1997). Manifesto for a relational sociology. American Journal of Sociology, 103(2), 281-317.

Hager, P. \& Halliday, J. (2006). Recovering informal learning: Wisdom, judgement and community. (Dordrecht: Springer)

Hager, P. \& Beckett, D. (forthcoming). The Emergence of Social Complexity: Practice and Learning Reconceptualised. (Dordrecht: Springer)

Heidegger, M. (orig. 1954; 1972, J. Glenn Gray \& F. Wieckwith (Trans). What is called thinking? (New York: Harper and Row)

Lancaster, J. (2012). The complex systems of practice. (In P. Hager. A. Lee \& A. Reich (Eds.), Practice, learning and change: Practice theory perspectives on professional learning, (pp. 119-131) Dordrecht: Springer.)

Lancaster, J. (2013). Complexity and relations. Educational Philosophy and Theory, 45 (12), $1264-1275$ 
List, C. \& Pettit, P. (2011). Group agency: The possibility, design and status of corporate agents. (Oxford University Press, New York)

Malpas, J. (2002). The weave of meaning: Holism and contextuality. Language and Communication, 22, 403-419.

Morin, E. (2007). Restricted complexity, general complexity. (In D. Aerts, C. Gershenson \& B. Edmonds, Worldviews, science and us: Philosophy and complexity. (pp. 5-29) Singapore: World Scientific Publishing.)

Nicolis, G. (1995). Introduction to nonlinear science. (Cambridge: Cambridge University Press)

Polanyi, M. (1966). The tacit dimension. (New York: Doubleday \& Co) Ch.1

Richardson, K. \& Cilliers, P. (2001). What is complexity science? A view from different directions. Emergence, 3(1), 5-23

Rosen, R. (1987). Some epistemological issues in physics and biology. (In B.J. Hiley \& F.D. Peat (Eds.) Quantum implications: Essays in honour of David Bohm. (pp. 314-327) London: Routledge.

Rovane, C. (2014). Group agency and individualism. Erkenntnis, (Supplement 9: Group agency and collective intentionality), 79, 1663-1684

Simpson, D. \& Beckett, D. (Eds) (2014). Special issue: Expertise, pedagogy and practice. Educational Philosophy and Theory, 46 (6)

Tollefsen, D. P. (2015). Groups as agents. (Cambridge UK: Polity Press)

Verran, H. (2001). Science and an African logic. (Chicago: University of Chicago Press)

Watson-Verran, H., with the Yolngu community at Yirrkala and David Wade Chambers (1989). Singing the land, signing the land. (Geelong, Vic. Deakin University Press) 